\title{
A qualidade "de dentro" na/da pesquisa qualitativa em Educação do Sul do Brasil
}

\section{The quality "inside" in/of the qualitative research in Education in Brazil south}

\author{
Eliane Juraski Camillo*
}

\begin{abstract}
RESUMO
O presente artigo trata sobre a qualidade na pesquisa qualitativa dos programas de pós-graduação, na área da Educação, de duas instituições do Sul do Brasil: Universidade Federal de Santa Catarina (UFSC) e Universidade Federal do Paraná(UFPR). O intuito é compreender, entre os pós-graduados, egressos do doutorado que defenderam suas teses no biênio 2013/2014, os sentidos e o espaço que são atribuídos à qualidade na/da pesquisa em Educação. Estes são percebidos pela preocupação que os doutores tiveram (ou não) ao fazerem suas teses e pelos critérios ou estratégias que adotaram em prol da qualidade, bem como os elementos que demonstram que sua tese pode ser considerada de qualidade. Para efetivar esse estudo, utilizou-se a pesquisa qualitativa on-line, através da internet, com aporte em Flick, por intermédio de questionário enviado por e-mail aos sujeitos como instrumento de produção de dados. Os retornos apontam para o fato de que os doutores egressos que responderam ao questionário - UFSC e UFPR - observaram as estratégias favoráveis à qualidade durante todo o processo de pesquisa, ainda anterior ao início propriamente dito. Isso permite que se declare que a qualidade na/da pesquisa qualitativa em Educação, nessas duas universidades, é uma preocupação, sendo construída a partir dos "de dentro", que são os próprios sujeitos/doutores egressos.

Palavras-chave: Educação. Pesquisa qualitativa em Educação. Pesquisa qualitativa on-line. Qualidade.
\end{abstract}

DOI: $10.1590 / 0104-4060.47999$

* Instituto Federal de Santa Catarina. Centro de Referência e Educação a Distância. Florianópolis, Santa Catarina, Brasil. R. Duarte Schutel, nº 99. Centro. CEP: 88015-640. E-mail: juraskicamillo@gmail.com 


\begin{abstract}
This article deals with the issue of quality in education research, in two programs of graduation in education in two institutions in the south of Brazil: the Universidade Federal de Santa Catarina (UFSC) and the Universidade Federal do Paraná (UFPR). The study had the aim of understanding the meanings and the space assigned to the quality in/of educational research, among graduate students that defended their theses and dissertations in the biennium 2013/14, from the perceived concern that doctors had (or didn't have) in the composition of their dissertations. We also studied which criteria and strategies were adopted for the sake of quality, as well as which elements show that those can be considered of quality. To carry out this study, we used online qualitative research through the internet, with basis on Flick, by the way of a questionnaire sent by email to the subjects as a data production tool. The results point to the fact that the graduated doctors who responded to the questionnaire - in UFSC and UFPR - observe the strategies conductive to quality throughout the research process, even before its beginning proper. This allows me to declare that the quality in/of qualitative research in education is a concern among the students of these universities, being built from the "inside"; that is, the subjects/graduated doctors themselves.

Keywords: Education. Qualitative research in education. Online qualitative research. Quality.
\end{abstract}

\title{
Iniciando a conversa
}

Antes de tratar da qualidade na/da pesquisa qualitativa em Educação, considero de relevância dispensar algumas palavras no sentido de bem demarcar sobre o que falo quando menciono a pesquisa em Educação e que conflui para a questão da qualidade.

Primeiramente, o campo da Educação é considerado por Charlot (2006) como epistemologicamente fraco por não ter fronteiras bem definidas. Trata-se de um campo que o autor denomina de mestiço, em que se entrecruzam saberes, práticas e políticas de diversas áreas. Consequentemente, a Educação é um campo saturado de discursos múltiplos, sendo difícil, inclusive, levantar e delimitar novos problemas.

Embora abrigando esses vários discursos, a pesquisa na área da Educação precisa ter uma especificidade, uma identidade que a diferencie de outros campos. Caso contrário, ter-se-á uma pesquisa sobre educação e não em educação. 
Nosella (2010), com o qual me associo, aponta alguns problemas e deficiências dos mestrados e doutorados e das dissertações e teses no campo da Educação. Dentre outras, o autor alude à pressão por produção (e essa essencialmente acadêmica); a necessidade de revigorar a teoria, já que, para o autor, o pesquisador precisa ter uma linha teórica séria e precisa, como o fio de Ariadne, que lhe permita sair do labirinto da irracionalidade e do solipsismo, representados principalmente pela justaposição, em lugar da articulação, entre referenciais teóricos, recaindo na falta de organicidade. $\mathrm{O}$ autor também manifesta preocupação com o fato de melhorar as narrativas: o cientificismo e a literatura devem andar juntos na tessitura do relatório. Esses problemas se relacionam, sobremaneira, com a questão da qualidade das pesquisas qualitativas em Educação.

Campos (2009) considera, na pesquisa em Educação, a desconexão entre elas e as realidades educacionais/escolares. Ao passo que a pesquisa, agora institucionalizada por intermédio dos programas de pós-graduação, aumentou quantitativamente, todavia nem sempre é possível afirmar que o mesmo ocorreu/ ocorre em matéria de qualidade.

Neste escrito, lançarei um olhar sobre a qualidade na/da pesquisa qualitativa em Educação, elegendo o ponto de vista de doutores sobre a qualidade de suas teses. Mas, de que qualidade falo?

\section{O que diz a literatura teórica}

Flick esclarece, antes de se adentrar na questão da qualidade propriamente dita, que a pesquisa qualitativa não é tão somente a pesquisa não quantitativa ou oposta a esta, mas desenvolveu identidade(s) própria(s), por vezes, difícil de definir com exatidão. No entanto, a pesquisa qualitativa tem, como característica geral que a identifica, o fato de se ocupar em estudar o mundo "lá fora" (FLICK, 2009a, p. 8), mais precisamente os seus fenômenos, de uma maneira distinta da pesquisa quantitativa, que, via de regra, estuda os fenômenos em contextos especiais, como os laboratórios. A pesquisa qualitativa analisa experiências e examina interações que se desenvolvem em seus contextos, de modo amplo, não tendo, portanto, o forte controle sobre as variáveis como na pesquisa quantitativa.

Devido à dificuldade em defini-la com exatidão, adicionada ao aumento do interesse pela pesquisa qualitativa, tanto no âmbito acadêmico quanto fora dele, a preocupação com a qualidade se torna imperativa, além de uma questão um tanto difícil de se estabelecer. $\mathrm{O}$ autor vaticina que o foco das discussões acerca da qualidade na pesquisa qualitativa precisa se deslocar de níveis fundamentais, 
epistemológicos e filosóficos para níveis concretos. Ou seja, a "qualidade de fora" precisa dar lugar para a "qualidade de dentro".

A "qualidade de fora" é esmiuçada pelo autor, tendo por base alguns elementos, tais como o interesse das instituições de financiamento em avaliar o que deveria ser ou o que já foi financiado; o interesse dos editores de publicações acadêmicas na decisão sobre o que publicar e o que não publicar, (ambos evidenciando a competição no que tange a critérios de financiamento/ publicação); o interesse dos leitores sobre qual pesquisa é digna de confiança; sem contar com o planejamento de currículos, campo este, a exemplo de muitos outros, não revestido de neutralidade, em que ocorrem disputas, sendo que no caso específico de disciplinas concernentes à pesquisa, pode sobrevir o embate - discorrido por vários autores - quantitativo versus qualitativo. $\mathrm{O}$ autor manifesta preocupação quando a ênfase recai sobre esses fatores de fora: isso pode levar à padronização, a qual, pela própria feição da pesquisa qualitativa, não pode servir de base para avaliá-la. Outro ponto problemático é que, vindo de fora, geralmente a qualidade da pesquisa qualitativa é avaliada por intermédio de critérios que geralmente compõem uma (longa) lista de itens a serem satisfatoriamente atendidos. E o autor manifesta apreensão quanto ao fato de os critérios serem adequados à pesquisa qualitativa ou à pesquisa quantitativa, pela necessidade de financiamento/publicação/reconhecimento, acabar se adequando aos critérios de forma artificial. Ora, os critérios devem ser funcionais e não adquirirem vida própria. Os itens precisam ser usados porque se adequam ao estudo, e não atendidos de modo forçado, simplesmente porque aumentam as chances de publicação ou financiamento, o que, indubitavelmente, desvirtua a pesquisa qualitativa, imprimindo-lhe um caráter mercadológico, alinhando-a às cadências capitalistas.

Sobre esse quesito, também Nosella (2010) se posiciona favoravelmente a que o processo de avaliação da pesquisa em Educação seja revisto. Para ele, ao invés de regras determinadas a priori, o que deveria determinar a qualidade de uma pesquisa é a sua contribuição no sentido de humanizar a sociedade e a natureza.

Por essas razões, Flick (2009b) expressa que a qualidade da pesquisa qualitativa deve predominar sobre a vertente "de dentro", a qual pode ser entendida como a apropriabilidade de métodos à pergunta de pesquisa e às decisões mais adequadas em relação à ética no processo de pesquisa. Indo além, a qualidade da pesquisa qualitativa precisa ser objeto constante de atenção dos pesquisadores, os quais devem ser os primeiros interessados em promovê-la, sob pena de sucumbirem às crescentes exigências de qualidade dos "de fora". Por isso é justificável sondar os sentidos e a preocupação com a qualidade junto aos próprios pesquisadores, que é o que aqui faço. Em função disso, Flick 
(2009b) admoesta que os critérios e listas de itens, nessa perspectiva, dão lugar a estratégias, que não apenas servirão para avaliar a qualidade do produto final da pesquisa, mas, sobretudo, fazer uma espécie de gerenciamento das fases da pesquisa, contribuindo assim para a promoção gradativa da qualidade. Qualidade, esta, entendida não somente como uma pesquisa com indicação de financiamento ou publicação, mas também como uma pesquisa que é, de fato, de qualidade porque apresenta avanços na construção do conhecimento e porque impacta positivamente no recorte espaciotemporal no qual é desenvolvida.

Flick (2009b) apresenta algumas estratégias favoráveis ao gerenciamento e à promoção da qualidade na pesquisa qualitativa. Adverte, no entanto, que tais estratégias não garantem terminantemente a qualidade, já que possuem também as suas limitações, todavia a auxiliam. A amostragem teórica aparece como uma espécie de ponte entre a teoria e a variância, ao passo que permite a abertura ao que está acontecendo no campo. As decisões relativas à etapa seguinte são tomadas levando-se em conta o que o campo revela, estando, portanto, em consonância com um dos principais motes da pesquisa qualitativa: a maleabilidade.

A indução analítica, em linhas gerais, permite uma atenção especial às exceções, em detrimento da norma. Todavia, o escopo em relação a ela é ampliado, passando a abarcar também exemplos, observações e declarações que não se ajustam bem à teoria ou à estrutura até então desenvolvida. Quando esses aspectos são levados em conta na pesquisa - ao invés de simplesmente ignorados ou descartados, como muitas vezes ocorre, já que o diferente pode nos causar incômodo - o pesquisador vê-se obrigado a empreender constante vigilância, enquanto reformulações se farão necessárias, o que conferirá maior qualidade à pesquisa. A estratégia propicia uma busca incessante ao novo: novas ideias, novas explicações, novas teorias, novos desafios, novos olhares, que são deveras assertivos no sentido de impactar positivamente sobre as diferentes realidades pesquisadas.

Na mesma direção da indução analítica, está o consenso de membros e públicos, ancorado na ideia da validação, considerando de preponderância uma segunda opinião, uma diferente visão, abrindo caminho e espaço para a diversidade. Igualmente, força o pesquisador a buscar novos caminhos, novas soluções, constituindo-se em uma maneira ricamente válida de gerenciar a diversidade, superar explicações prematuras e visões rápidas sobre os fenômenos estudados, promovendo, assim, a qualidade.

Inspirado principalmente em Norman Denzin, Flick (2009b) discorre acerca da triangulação, entendendo-a, excetuando-se, como declarei, os pontos fracos, como um mecanismo ótimo na promoção da qualidade na pesquisa qualitativa. A triangulação corresponde aos distintos prismas que o pesquisador pode assumir, visando diminuir os vieses. Quanto aos tipos, há a triangulação 
de investigadores, quando mais de um pesquisador lida com os mesmos dados, com o intuito de remover (ou diminuir) o viés proveniente do fato de uma só pessoa olhar para os dados; a triangulação de teorias, quando várias posturas teóricas são admitidas, permitindo comparação constante e avanço; a triangulação de dados, quando a pesquisa é desenvolvida com diferentes sujeitos, de vários lugares e em tempos diversos; e a triangulação de métodos, possível dentro de um método ou entre métodos, onde o ponto forte de um método tende a cobrir o ponto fraco de outro.

Alguns problemas quanto às triangulações podem advir de limitações de tempo e de dinheiro, já que fazer mais do que inicialmente programado no plano de pesquisa de fato o demandam. Também é preciso considerar a experiência do pesquisador, já que lidar com vários métodos, incluindo algum que eventualmente não tenha experiência e habilidade em trabalhar é passível de trazer alguns embaraços. Ainda, a triangulação eleva a profundidade da pesquisa, porém não conduz inevitavelmente à verdade verdadeiramente verdadeira, impossível de atingir. Isso, no entanto, não lhe subtrai o mérito, mesmo realizada em parte, de se consubstanciar em uma ferramenta deveras útil na gestão e promoção da qualidade na pesquisa qualitativa, orquestrada pelo olho atento do pesquisador, e não vinda "de fora".

O autor dispensa, ainda, algumas considerações acerca da ética. A pesquisa é, em face dessa dimensão, focalizada como uma intervenção que perturba o recorte em que é realizada. E essa perturbação apenas é justificável se a pesquisa for relevante, produzir coisas novas, impactar positivamente. Para isso, o pesquisador precisa estar consciente de não fazer falsas promessas, já que não é amigo, tampouco terapeuta. Alguns princípios éticos requerem observação por parte do pesquisador, como o consentimento informado e a informação constante no decorrer da pesquisa em prol dos sujeitos; o agir natural do pesquisador, sem tomar partido de pessoas e/ou situações; a proteção do anonimato dos sujeitos; a consciência de que os comitês de ética não resolvem todos os dilemas éticos da pesquisa, sendo que muitas decisões terão de ser tomadas pelo pesquisador no processo da pesquisa, demandando ser resultado de uma reflexão cuidadosa.

Exemplificando, nem todas as informações pertinentes ao sujeito precisam ser divulgadas no relatório da pesquisa. O pesquisador terá que estabelecer o limite equilibrado, às vezes tênue, entre o que é de supremo interesse na elucidação do problema elencado, tendo, portanto, de ser divulgado e problematizado, e alguma informação de relevância menor para a pesquisa e que traga algum melindre para o sujeito, podendo, por isso, não ser divulgada, preservando o(s) sujeito(s). Flick (2009b) defende que a pesquisa que não traz nada de novo é antiética, ou seja, somente a pesquisa de qualidade é ética. Contudo, essa relação, em determinados momentos, pode se subverter, tendo em conta que aprofundar 
alguma questão, sobretudo quando se trata de entrevistas com sujeitos vulneráveis, perseguindo uma maior qualidade, pode esbarrar em um problema ético, já que acaba por submeter mais uma vez o sujeito ao seu sofrimento.

Por fim, a ética também se associa à questão da transparência em todas as fases da pesquisa, incluindo nesse ínterim a tessitura do relatório final, no qual a escrita se reveste de reflexividade, capaz de fazer com que a pesquisa transmita seus objetivos ao(s) leitor(es), contribuindo para a sua qualidade.

\section{Descrevendo o caminho percorrido}

No que concerne à metodologia, este artigo é fruto de estudo no qual utilizei a pesquisa qualitativa on-line (através da internet), tendo como ferramenta de produção de dados a entrevista assíncrona, efetivada via questionário e enviada por intermédio de e-mail aos doutores que defenderam suas teses no biênio 2013-2014, em três universidades públicas federais do Sul do Brasil: Universidade Federal de Santa Maria (UFSM), Universidade Federal de Santa Catarina (UFSC) e Universidade Federal do Paraná (UFPR).

Flick (2009b) destaca o aumento pelo interesse do uso das tecnologias da comunicação e da informação na pesquisa social, principalmente da internet. Esse se dá, sobretudo, ancorado no vertiginoso desenvolvimento dessa(s) ferramenta(s), a qual tem servido tanto como fim de pesquisas quanto de meio. Assim como qualquer outro método, pois possui potencialidades e limitações, as quais devem ser levadas em conta - a exemplo do que procedi - no momento de se optar ou não por ele, observando primordialmente a apropriabilidade do método para se responder a(s) questão(ões) que um pesquisador se propõe quando inicia um estudo.

O autor salienta que uma das principais vantagens desse método é o fácil acesso aos sujeitos por um baixo custo, fator este que levei muito em conta no momento da minha opção. Realmente, caso fizesse entrevistas presenciais, teria que empreender vários deslocamentos para chegar até os sujeitos, já que o território abarcado é deveras amplo, o que se tornaria bastante oneroso, inviabilizando o estudo.

Um dos pontos negativos do método e que talvez tenha sido preponderante para a não participação de uma das universidades, a UFSM, é o fato de que a ausência de contato pessoal/presencial impede explicações mais pontuais e detalhadas sobre o estudo, de certa forma, o estabelecimento de uma empatia faz com que os sujeitos se sintam impulsionados a participar de uma pesquisa 
porque é significativa para eles. Tentei compensar isso enviando mais de uma mensagem reforçando o que eu estava fazendo, os objetivos e a relevância àqueles/àquelas cujo retorno não estava recebendo. Porém, foi em vão em relação aos doutores egressos da UFSM, dos quais não recebi retorno algum. Essa ausência, no entanto, foi compensada pela maciça participação dos sujeitos oriundos das outras duas universidades, especialmente da UFPR, da qual obtive a quase totalidade de retornos dos doutores egressos.

No tocante ao uso da pesquisa qualitativa, pude comprovar o que a totalidade dos autores, com os quais aqui dialogo, enunciam sobre o aumento do interesse e do uso deste tipo de pesquisa na Educação, constituindo uma quase unanimidade por conseguir abarcar mais aspectos do real do que a pesquisa quantitativa. Dito de outro modo, por essa razão, a pesquisa qualitativa é o tipo de pesquisa que vem se utilizando na educação, fato comprovado pelos sujeitos pesquisados.

Esclareço que contei com o retorno de dezesseis sujeitos da UFPR e doze da UFSC. Acrescento, ainda, que o recrutamento dos sujeitos iniciou com visita aos sites dos programas de pós-graduação em Educação das três universidades pesquisadas, o que também trouxe um dado importante, já que, em duas delas (UFSM e UFSC) não foi suficiente, dado que na UFSM a seção do site destinada às teses e às dissertações estava em construção, não sendo, portanto, possível tomar conhecimento delas por esse caminho; enquanto na UFSC estavam disponíveis apenas as dissertações de mestrado, que não eram o foco de meu interesse. A saída encontrada foi enviar e-mail ao endereço eletrônico das secretarias dos programas e pedir a informação. Resolvi encaminhar a mensagem às três secretarias, também à da UFPR, no sentido de auscultar algum egresso cuja tese porventura não estivesse ainda na página do programa, sendo que obtive a confirmação de que todas estavam. Nas outras duas universidades - UFSM e UFSC - demorou um pouco até minha mensagem ser respondida, tendo que encaminhá-la por mais vezes, até obter o retorno com a informação. De posse, então, dos nomes dos egressos e seus endereços de e-mails, teci, então, mensagem explicando do que se tratava a pesquisa e dos meus propósitos com ela, ao final, convidava-os a participarem. Após o assentimento, enviei nova mensagem, contendo o questionário.

O questionário enviado foi composto das seguintes perguntas: para você, qual/quais é/são o(s) significado(s) da qualidade na/da pesquisa qualitativa em Educação? O que uma pesquisa em Educação precisa ter ou observar para que se possa afirmar que a mesma é de qualidade? A questão da qualidade foi uma das preocupações quando da tessitura de sua tese? Você teve algum(ns) cuidado(s) no sentido de atingir a qualidade na sua tese? Quais? Que elementos de sua tese demonstram que a mesma pode ser considerada de qualidade? 


\section{Análises e reflexões}

Inicio as análises e reflexões acerca dos retornos que obtive, salientando, inicialmente, as respostas dadas à terceira questão, pois esta permite/permitiu a continuidade das averiguações que fiz/faço, já que, se os sujeitos - todos ou grande número deles - tivessem declarado que a qualidade não fosse de relevância, não teria elementos suficientes para continuar interrogando. Entretanto, todos os sujeitos foram unânimes em declarar que a qualidade de suas teses foi uma preocupação constante, desde a concepção, anterior ainda à formulação da pergunta, até a redação final. Isso confirma que a qualidade na/da pesquisa qualitativa em Educação é um elemento fortemente presente nas duas universidades participantes deste estudo, confluindo para que eu afirme que a "qualidade de dentro" está presente nesse recorte. Um dos sujeitos entende, inclusive, que não há uma cisão bem demarcada entre a "qualidade de dentro" e a "de fora". Há, na realidade, convergência e continuidade, já que entende que, no Brasil, ao menos na educação, uma pode ser considerada como prolongamento da outra, tendo em conta que, quando está presente em uma tese - o que se considera ser sinônimo de qualidade -, ela é bem vista e aceita pelos órgãos financiadores e de publicação. No entanto, não ficou claro, nesse caso, se a "qualidade de dentro" antecede, precede ou é motivada pela "de fora". Se precede ou for motivada, parece-me que se alinha com que Flick (2009b) se preocupa, que é o fato de que há preocupação com a qualidade quando o intuito é obter financiamento ou conseguir publicação - caráter mercadológico. Se antecede, é porque realmente há convergência e os vários polos envolvidos, a saber, pesquisadores e instituições compartilham de interesses e pontos de vista análogos.

Em relação aos significados de qualidade na/da pesquisa, cuidados na tessitura que a favorecessem e os elementos das teses que a demonstram, os fatores apontados foram diversos. A começar, conforme apontei, para alguns elementos anteriores à pesquisa propriamente dita.

As motivações que levam um pesquisador a escolher um determinado tema de pesquisa, e não outro, foi o primeiro fator apontado como favorável à qualidade. Os sujeitos fizeram menção à importância de se ter, minimamente, afinidade com o tema/temática da pesquisa. Para eles, uma intenção de pesquisa não nasce do nada, tampouco uma pesquisa, principalmente no doutoramento, pelo maior período e, consequentemente, maior investimento intelectual. Seria extremamente difícil trabalhar quatro anos com um tema pelo qual não se tem paixão, ou então, represente mais uma vontade do orientador do que do pesquisador. Nesse caso, na visão dos sujeitos, a pesquisa até pode chegar ao 
seu término, mas certamente não terá o mesmo esplendor do que quando o pesquisador possui interesse genuíno pelo assunto, pressupondo o envolvimento, a entrega, sem perder de vista, no entanto, o distanciamento necessário para não se incorrer em viés, em consonância com a preocupação de Flick (2009b).

A questão do tema/temática de pesquisa também é enunciada pelos sujeitos pelo viés do compromisso social do pesquisador, o qual tem a obrigação de devolver à sociedade um conhecimento novo, inédito, capaz de minimamente modificar a sociedade (parte dela) e/ou a natureza. Esse compromisso é ainda maior por se tratar de universidades públicas, conforme os sujeitos recordaram, e ainda mais quando bolsistas, caso em que as pesquisas são duplamente financiadas com dinheiro público, fazendo-se imperioso a devolutiva.

Outra preocupação apontada pelos sujeitos foi a apropriabilidade, discorrida também por Flick. Ela diz respeito, sobretudo, à observância da coerência entre a pergunta de pesquisa, o referencial teórico adotado e sua relação com os métodos e a natureza dos dados produzidos e analisados, confluindo para a coerência interna da tese. Tudo isso sem perder de vista o caráter maleável, característica cara da pesquisa qualitativa, permitindo, nas muitas idas e vindas, as adequações essenciais para que os objetivos - geral e específico - sejam atingidos, respondendo-se, assim, satisfatoriamente à(s) questão(ões) da pesquisa, tendo sempre o rigor e a cientificidade como baluartes.

Os doutores egressos das duas universidades enfatizaram a significância de se buscar constantemente aporte na literatura teórica, o que já foi produzido sobre o tema de estudo; na literatura empírica, pesquisas feitas anteriormente; e na literatura metodológica, sobre como realizar a pesquisa, métodos e técnicas, o que também é dissertado por Flick (2009a). Dessa forma, haverá uma retroalimentação bastante salutar para os novos estudos.

Como alguns sujeitos eram oriundos de linha de pesquisa que encadeava Educação e História da Educação, foram destacados, nas respostas, alguns cuidados dignos de nota. A busca e a seleção das fontes, já que os acervos de pesquisa geralmente são gigantescos, faz com que seja preciso delimitar o que servirá para dar as respostas que se busca com a pesquisa. Após, aparece a crítica às fontes: elas não falam por si mesmas, no máximo é possível interpretá-las, o que inclui aspectos da objetividade dos documentos e da subjetividade (dentro de limites próprios) do(a) próprio(a) pesquisador/pesquisadora. O policiamento quanto ao anacronismo igualmente deve nortear o caminho da pesquisa para não se incorrer no erro de tomar e julgar o passado com os olhos (mentalidade) do presente. Na esteira disso, os sujeitos alegam que se deve trabalhar na perspectiva de movimento do objeto investigado, ainda que demarcado em um dado período cronológico, por ele não ser estático, sendo preciso percebê-lo aquém e além do tempo histórico demarcado. Enfatizou-se, também, a necessidade de resistir 
à paixão às fontes/documentos, pois, por vezes, nessa perspectiva de pesquisa, pode ocorrer o fascínio aos documentos sem a compreensão do momento em que foi produzido ou de quem o produziu. O que era sociedade naquele momento e o que faziam os sujeitos quando produziram tais documentos, resistindo, assim, à(s) primeira(s) impressão(ões), sem contar do afastamento suficiente do objeto para resistir à paixão, mas ficando próximo o bastante para apreendê-lo, o que arrisco afirmar que deve ser observado em outras perspectivas de pesquisa qualitativa em Educação, não apenas nas de cunho historiográfico.

Parte dos sujeitos citou que se utilizou da amostragem teórica (FLICK, 2009b) e que esta foi positiva no processo de pesquisa por permitir uma maior maleabilidade, já que as decisões pertinentes aos passos seguintes levavam em consideração o que ocorria no momento presente, principalmente no que diz respeito a indicações e pistas deixadas pelos próprios sujeitos pesquisados no âmbito das teses.

A indução analítica e o consenso de membros (FLICK, 2009b; MAY, 2004) também foram considerados elementos indicadores de qualidade observados e presentes nas teses, segundo seus sujeitos, que manifestaram, em relação à primeira, dispensar atenção não apenas às informações que estavam buscando, mas também aos casos desviantes que, em muitos ensejos, redirecionavam os rumos do trabalho, revelando-se de preponderância na construção do conhecimento. Pertinente ao último, possibilitou a validação das entrevistas junto aos entrevistados, diminuindo os males entendidos e igualmente contribuindo para o aumento da credibilidade das informações produzidas.

Por fim, os sujeitos ainda apontaram o uso da triangulação (FLICK, 2009b) de teorias, já que vários autores, de várias correntes teóricas foram utilizados pelos doutores egressos; de dados, pois a maioria deles produziu dados em diferentes tempos, espaços e junto a diferentes sujeitos; e a de métodos, já que, igualmente, alguns declararam que, quanto à metodologia, usaram, na tessitura da tese, diversos métodos combinados, tais como grupo focal, observação participante e entrevista; análise documental e entrevista.

\section{Finalizando a conversa}

Concluindo, as respostas dos sujeitos permitem-me declarar que uma pesquisa de qualidade em Educação ou em qualquer outra área é aquela que se fundamenta na literatura e em pesquisas anteriores, que possui uma justificativa social e científica adequada e que, principalmente, cumpre os objetivos a que se 
propõe e, para isso, faz uso de metodologias precisas e válidas de acordo com os critérios científicos.

Os doutores egressos das duas universidades públicas federais que retornaram os questionários manifestaram preocupação com a qualidade de suas teses em todo o processo da pesquisa, ainda anterior ao início, o que demonstra que a qualidade não é algo pronto, mas vai se construindo conforme o estudo avança.

A observância dos múltiplos aspectos analisados e revelados pelos doutores egressos, em consonância com minha abordagem teórica eleita sobre a qualidade na/da pesquisa qualitativa em Educação, autoriza-me a afirmar que, no recorte pesquisado, a qualidade na pesquisa qualitativa em Educação é uma preocupação constante, de singular importância. Havendo a "qualidade de dentro", perceptível nas estratégias adotadas pelos sujeitos, estes/estas não ficarão submetidos a critérios de qualidade advindos dos "de fora".

\section{REFERENCIAS}

CAMPOS, M. M. Para que serve a pesquisa em Educação? Cadernos de pesquisa, v. 39, n. 136, p. 269-283, jan./abr. 2009. Disponível em: <http://www.scielo.br/scielo. php?script=sci_arttext\&pid=S0100-15742009000100013>. Acesso em: 03 set. 2014.

CHARLOT, B. A pesquisa educacional entre conhecimentos e práticas: especificidades e desafios de uma área. Revista Brasileira de Educação, v. 11, n. 31, p. 7-18, jan./ abr. 2006. Disponível em: <http://www.scielo.br/scielo.php?script=sci_arttext\&pid $=$ S1413-24782006000100002 $>$. Acesso em: 03 set. 2009 .

FLICK, U. Introdução à pesquisa qualitativa. 3. ed. Porto Alegre: Artmed, 2009a.

FLICK, U. Qualidade na pesquisa qualitativa. Porto Alegre: Bookman, 2009b.

MAY, T. Pesquisa social: questões, métodos e processos. 3. ed. Porto Alegre: Artmed, 2004.

NOSELLA, P. A pesquisa em Educação: um balanço da produção dos programas de pós-graduação. RBEP, v. 15, n. 43, jan./abr. 2010.

Texto recebido em 08 de agosto de 2016. Texto aprovado em 14 de dezembro de 2016. 